\title{
View of UK medical students on interacting with multicultural patients: is it a natural or a taught skill?
}

\author{
Samiullah Dost, Bilal Master, Salman Momin, Ahmed Najjar, Faisal Jamshaid and Ziyan Kassam \\ Kings College London, London, UK
}

As final year medical students from London, we all had a great deal to learn from the article by HyeRin Roh and Lauren Nirta titled "Medical students interact with multicultural patients to learn cultural diversity [1]." We became interested in this topic as our experience in London was in stark contrast to that of medical students in South Korea. Studying in London puts us in a unique position to interact with people from many cultures in clinics and outside clinics, thus we have naturally developed an awareness and understanding of different cultures and beliefs. We believe being aware of a patient's cultural background can aid their care in certain clinical settings. This process can either be taught such as that attempted by HyeRin Roh and Lauren Nirta in their study or it can be a naturally gained skill, as we feel we have gained as medical students studying in London.

The General Medical Council (GMC) in the United Kingdom recognizes the importance of diversity in patient care and educating future physician. In Tomorrows Doctors published by the GMC it strongly highlights the need for diversity and equality education in the medical schools [2]. However, we feel there is a gap between the GMC guidelines and what we have experienced in our medical education. We have not had any diversity training during our medical school education nor have we felt the need to. This educational gap between what the GMC guidelines and our medical education is filled by the fact that we are students in London, thus we have picked up on issues of diversity and equality naturally from our day to day interactions. Other students in less diverse areas of the United Kingdom might miss out on this aspect of their medical education if enough importance is not placed on this topic. This gap may be due to medicine being perceived as a strictly facts-based science subject both by students and the faculty, thus placing less importance on behavioral sciences aspect of the curriculum which addresses issues of diversity and equality [3].

London is one of the most diverse cities in the world, with 55\% of Londoners being non-white [4]. Ethnicity, race, and religion have become an ever more important
Received: June 26, 2018 • Revised: August 6, 2018 • Accepted: August 14, 2018 Corresponding Author: Samiullah Dost (https://orcid.org/0000-0001-9088-613X) Kings College London, Guy's Campus, London, SE1 1UL, UK

Tel: +44.7947671828 Fax:+44.0208937465 email: samiullah.dost@kcl.ac.uk
Korean J Med Educ 2018 Sep; 30(3): 261-263.

https://doi.org/10.3946/kjme.2018.101

eISSN: 2005-7288

(C) The Korean Society of Medical Education. All rights reserved. This is an open-access article distributed under the terms of the Creative Commons Attribution Non-Commercial License (http:// creativecommons.org/licenses/by-nc/3.0/), which permits unrestricted non-commercial use, distribution, and reproduction in any medium, provided the original work is properly cited. 
influence in delivering patient care due to an increasingly diversified population. In certain areas of London with a high concentration of one ethnicity, it is of paramount importance to be aware of the local population's cultural and religious beliefs. For example, in the provision of mental health services to the Bangladeshi community in East London, understanding their Islamic faith allows better understanding of their symptoms and gives it context and ultimately allows better patient care [5].

Diversity is also reflected in the UK National Health Service (NHS), non-white people make up $18 \%$ of the NHS workforce, 54\% of hospital consultants are white, 26\% Asian, and 5\% black. Diversity in healthcare starts with diversity in medical training. Fifty-three percent of doctors in training are white, 23\% Asian, and 10\% black [6]. We believe the combination of diversity in healthcare roles and patient populations allows for better medical and non-medical provision of care. This can range from understanding the context of mental health symptoms in certain cultures to being aware of specific types of food and dress patients might require due to religious reasons. Though there are differences between cultures, from our experience in the hospital, a general awareness of cultural and religious beliefs can enhance a patient's experience and care.

In countries such as South Korea, less exposure to a variety of cultures in healthcare and patient population during medical school creates challenges in effective training. This is vastly different to our experience in London, where we have naturally been educated on issues of diversity and cultural differences, even though, in our experience our medical school has lacked in delivery of formal diversity education. Medical schools in areas of the United Kingdom where exposure to multicultural patients is limited, need to pay more attention to the GMC guidelines. Educational pro- grammes can be integrated into their medical education such as those attempted in this study, this can be slowly achieved through online e-learning packages throughout preclinical and clinical years.

\section{ORCID:}

Samiullah Dost: https://orcid.org/0000-0001-9088-613X; Bilal Master: https://orcid.org/0000-0001-8325-8151; Salman Momin: https://orcid.org/0000-0002-0171-4385; Ahmed Najjar: https://orcid.org/0000-0002-2426-0179; Faisal Jamshaid: https://orcid.org/0000-0002-4314-2987; Ziyan Kassam: https://orcid.org/0000-0002-9450-014X Acknowledgements: None.

Funding: None.

Conflicts of interest: No potential conflict of interest relevant to this article was reported.

Author contributions: Study conception and design: SD; research of literature: BL, ZK; analysis and interpretation of literature: AN, FJ; drafting of the manuscript: SM; and critical revision: SD.

\section{References}

1. Roh H, Nirta L. Medical students interact with multicultural patients to learn cultural diversity. Korean J Med Educ. 2018;30(2):161-166.

2. General Medical Council. Outcomes for graduates (Tomorrow's Doctors). https://www.gmc-uk.org/-/media/ documents/outcomes-for-graduates-jul-15-1216_pdf61408029.pdf. Published July 2015. Accessed August 5, 2018.

3. Dogra N, Karnik N. Teaching cultural diversity to medical students. Med Teach. 2004;26(8):677-680.

4. Office for National Statistics, National Records of Scotland, Northern Ireland Statistics and Research 
Agency. UK Data Service: 2011 census aggregate data. https://doi.org/10.5257/census/aggregate-201 I-2. Published February 2017. Accessed August 6, 2018.

5. Littlewood R, Dein S. 'Islamic fatalism': life and suffering among Bangladeshi psychiatric patients and their families in London: an interview study 2. Anthropol Med. 2013;20(3):264-277.

6. National Health Service. NHS Employers Website: https://www.nhsemployers.org//media/Employers/Publicat ions/Ethnicity-in-the-NHS.pdf. Accessed June 22, 2018. 